\title{
Tumour tissue sampling for lung cancer management in the era of personalised therapy: what is good enough for molecular testing?
}

\author{
Lucia Kim¹, Ming Sound Tsao ${ }^{2,3}$ \\ Number 5 in the series "Challenges and controversies in thoracic oncology" \\ Edited by J-P. Sculier, B. Besse and P. Van Schil
}

\begin{abstract}
Affiliations: 'Dept of Pathology, Inha University School of Medicine, Incheon, South Korea. ${ }^{2}$ Princess Margaret Cancer Centre, University Health Network, University of Toronto, ON, Canada. ${ }^{3}$ Dept of Laboratory Medicine and Pathobiology, University of Toronto, ON, Canada.
\end{abstract}

Correspondence: Ming Sound Tsao, Princess Margaret Cancer Centre, 610 University Ave., Toronto, ON, M5G 2M9, Canada. E-mail: Ming.Tsaođuhn.ca

ABSTRACT In the era of personalised cancer therapy, the demand for molecular profiling of the patient's tumour is steadily increasing. In advanced nonsmall cell lung cancer (NSCLC) patients, testing for epidermal growth factor receptor (EGFR) mutations and anaplastic lymphoma kinase (ALK) gene rearrangements has become an essential component of clinical practice to select patients who are most likely to benefit from EGFR and ALK tyrosine kinase inhibitors, respectively. Furthermore, obtaining tissue specimens from recurrent or metastatic tumours or from patients who develop resistance to initial effective therapies are essential for our understanding of the molecular basis of tumour progression and development of drug resistance. Therefore, the sampling of tumour tissue that is representative and is adequate in quantity and quality for pathological diagnosis and genomic profiling is crucial. In this review, we will discuss factors that should be considered in obtaining and processing biopsy specimens to enable routine molecular analysis in NSCLC patients.

@ERSpublications

Personalised therapy: adequate tumour tissue sampling for pathological diagnosis and molecular profiling is critical http://ow.ly/yRjDM

Previous articles in this series: No. 1: Powell HA, Baldwin DR. Multidisciplinary team management in thoracic oncology: more than just a concept? Eur Respir J 2014; 43: 1776-1786. No. 2: Shlomi D, Ben-Avi R, Balmor GR, et al. Screening for lung cancer: time for large-scale screening by chest computed tomography. Eur Respir J 2014; 44: 217-238. No. 3: De Ruysscher D, Nakagawa K, Asamura H. Surgical and nonsurgical approaches to small-size nonsmall cell lung cancer. Eur Respir J 2014; 44: 483-494. No. 4: Van Schil PE, Opitz I, Weder W, et al. Multimodal management of malignant pleural mesothelioma: where are we today? Eur Respir J 2014; 44: 754-764.

Received: Nov 122013 | Accepted after revision: June 222014 | First published online: Aug 072014

Support statement: L. Kim was partially supported by a fellowship from the Terry Fox Foundation Training Program in Molecular Pathology of Cancer at CIHR (STP53912). M.S. Tsao is the M. Qasim Choksi Chair in Lung Cancer Translational Research. This work was partially supported by the Ontario Ministry of Health and Long Term Care.

Conflict of interest: Disclosures can be found alongside the online version of this article at erj.ersjournals.com Copyright @ERS 2014 


\section{Introduction}

During past decades, extensive efforts have been devoted to overcoming the lethality of cancers. However, the effectiveness of chemotherapeutic agents has reached a plateau [1]. Once cancers have metastasised, they are rarely curable as they almost invariably recur following initial chemotherapies. The recent discovery of driver mutations and their association with greater responsiveness to specific targeted agents led to a paradigm shift in cancer treatment from conventional chemotherapy to biomarker-driven targeted therapy. This new era of personalised therapy brings an increasing demand for characterisation of tumour genotypes and phenotypes. More than two-thirds of patients with nonsmall cell lung cancer (NSCLC) are in an advanced, inoperable stage at diagnosis [1]. Therefore, for most of them, small biopsy or cytology specimens will be the only available tissue for both diagnosis and molecular profiling. Furthermore, many investigators have recently focused on obtaining greater understanding of the molecular pathology of recurrent, metastatic or drug-resistant tumours. Therefore, repeat biopsy is assuming a greater role as the next generation of biological specimens. The latter can be defined as clinical specimens obtained from patients at distinct time-points in the course of disease or during the treatment period for tumour analysis to decide ongoing treatment options [2].

Mutations on the tyrosine kinase domain of epidermal growth factor receptor (EGFR) and rearrangement involving the anaplastic lymphoma kinase $(A L K)$ gene are closely associated with high response rates to their respective targeted tyrosine kinase inhibitors (TKIs) [3-5] and, thus, are the major determinants for therapeutic use of these TKIs [6-10]. Testing of patient tumour samples for EGFR mutations and ALK gene rearrangement has become an essential component of clinical oncology and pathology practice, and is currently considered a standard of care for advanced stage lung adenocarcinoma patients.

The first step for molecular genotyping is the sampling of adequate tumour tissue. The accuracy of molecular tests depends on sample quality as much as the molecular analyses themselves, emphasising the importance of good sample collection and proper processing techniques [11].

\section{The selection of biopsy site}

Selection of the lesions for biopsy is usually decided by the clinicians, surgeons or interventional radiologists. The genetic analysis from a single biopsy specimen may not cover the entire tumour's characteristics and may under-represent the heterogeneous genetic profile of the tumour [12]. Recent genomic studies have demonstrated the heterogeneity and genetic evolution in different regions of the same tumour, between primary and metastatic tumours, and between different metastatic sites. Despite this apparent heterogeneity, key driver mutations are well preserved in the metastatic as well as the primary tumours [13-15]. This suggests that genomic profiles of the primary tumour are likely to reflect the genomic spectrum of the metastasis, and the primary tumour tissue can be a surrogate for genomic profiling of all tumours [14]. A majority of EGFR mutations and $A L K$ gene rearrangements, as driver mutations of NSCLC, appear to follow this pattern.

There has been controversy about the heterogeneity of EGFR mutations in primary tumours and between primary and metastatic tumours [16]. Some systematic studies using laser-captured microdissection reported that $24-50 \%$ of NSCLC showed a heterogeneous population of EGFR mutated and non-mutated tumour cells [17-21]. Furthermore, patients with intra-tumoural EGFR heterogeneity had a tendency to show lower response rates to EGFR-TKI treatment (table 1) [18, 20]. When applying highly sensitive detection methods such as next-generation sequencing, subpopulations of EGFR exon 19 deletion showing different deletion patterns from the main type were detected in $43 \%$ of NSCLCs, but only $4 \%$ of tumours showed substantial subpopulations of deletions representing $>2 \%$ of genomic DNA [25]. However, other studies using manual microdissection failed to show intra-tumoural heterogeneity of EGFR mutations [22-24]. In addition, studies comparing EGFR mutation status of biopsies and resection specimens revealed no discrepancies (table 2) [26-28]. This suggests that, in some NSCLCs heterogeneous for EGFR mutation $[17,29,30]$, the number of tumour cells showing different mutational patterns in the primary tumour is very small and, thus, easily obscured by the predominant population and not detectable with usual methods. However, this intra-tumoural heterogeneity of EGFR mutations might partially account for the discrepancies in clinical response to EGFR-TKIs in EGFR-mutated patients and for cases with unexplained primary and secondary resistance $[28,31,32]$. In the clinical setting, the overall EGFR status of the cancer tissue appears more important and, in most patients, intra-tumoural mutation heterogeneity may not significantly affect the efficacy of EGFR-targeted treatment [28]; however, further confirmation is needed. According to the recent College of American Pathologists (CAP)/International Association for the Study of Lung Cancer (IASLC)/Association for Molecular Pathology (AMP) guideline on molecular testing in NSCLC, EGFR testing of multiple different areas within a single tumour is not necessary [33]. By contrast, for patients with multiple lung adenocarcinomas that seem not to originate from a single tumour, each 


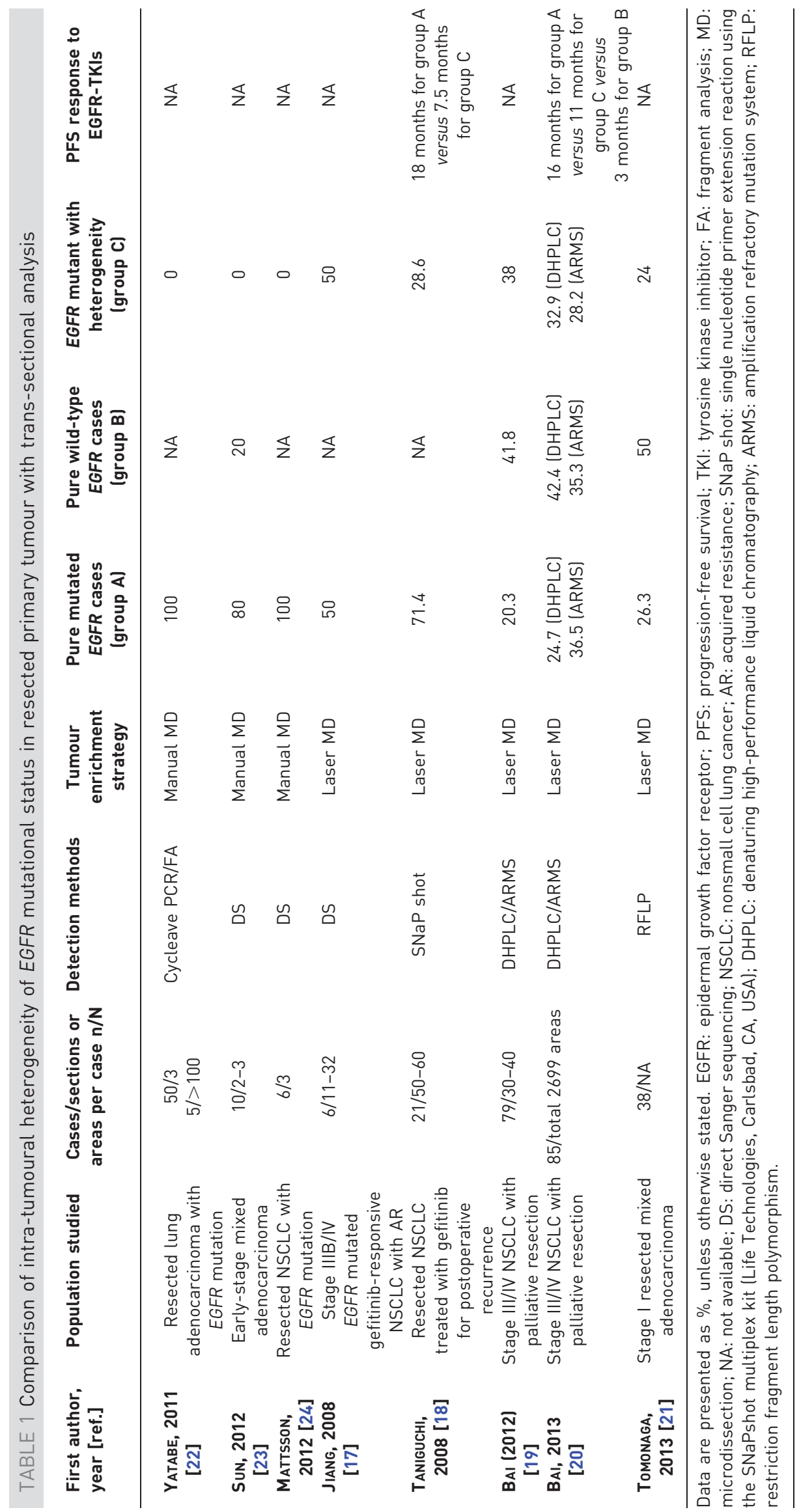


TABLE 2 Comparison of EGFR mutational status of biopsy and resected non-small cell lung cancer specimens

\begin{tabular}{|c|c|c|c|c|c|c|c|c|c|}
\hline $\begin{array}{l}\text { First author, } \\
\text { year [ref.] }\end{array}$ & $\begin{array}{l}\text { Population } \\
\text { studied }\end{array}$ & $\begin{array}{l}\text { Cases with } \\
\text { paired } \\
\text { biopsy and } \\
\text { resection } n\end{array}$ & $\begin{array}{l}\text { Detection } \\
\text { methods }\end{array}$ & $\begin{array}{c}\text { Tumour } \\
\text { enrichment } \\
\text { strategy }\end{array}$ & $\begin{array}{c}\text { EGFR } \\
\text { mutation in } \\
\text { both biopsy } \\
\text { and resection }\end{array}$ & $\begin{array}{l}\text { EGFR WT } \\
\text { in both } \\
\text { biopsy and } \\
\text { resection }\end{array}$ & $\begin{array}{c}\text { EGFR } \\
\text { mutation in } \\
\text { biopsy and } \\
\text { EGFR WT in } \\
\text { resection }\end{array}$ & $\begin{array}{l}\text { EGFR WT in } \\
\text { biopsy and } \\
\text { EGFR mutation } \\
\text { in resection }\end{array}$ & $\begin{array}{c}\text { Discordance } \\
\text { rate between } \\
\text { biopsy versus } \\
\text { resection }\end{array}$ \\
\hline $\begin{array}{l}\text { SOLOMON, } \\
2010 \text { [26] }\end{array}$ & $\begin{array}{c}\text { Stage I/II ADC } \\
\text { (neoadjuvant } \\
\text { gefitinib) }\end{array}$ & 16 & DS & NA & 31.3 & 68.7 & 0 & 0 & 0 \\
\hline \multirow[t]{2}{*}{$\begin{array}{l}\text { HAN, } \\
2012 \text { [28] }\end{array}$} & $\begin{array}{l}\text { Paired biopsy } \\
\text { and resection } \\
\text { with }\end{array}$ & 23 & DS & NA & 52.2 & 47.8 & 0 & 0 & 0 \\
\hline & $\begin{array}{l}>20 \% \text { tumour } \\
\text { cellularity }\end{array}$ & & $\begin{array}{c}\text { PNA } \\
\text { clamping }\end{array}$ & & 52.2 & 30.4 & 17.4 & 0 & 17.4 \\
\hline
\end{tabular}

Data are presented as \%, unless otherwise stated. EGFR: epidermal growth factor receptor; WT: wild-type; ADC: adenocarcinoma; DS: direct Sanger sequencing; NA: not available; MD: microdissection; PNA: peptide-nucleic acid. \#: the amount of DNA from one biopsy specimen was not sufficient and only one exon (exon 19) was sequenced and demonstrated to be wild type, and the corresponding resection specimen showed L858R mutation in exon 21; therefore, this case was not counted as discordant.

tumour may be tested separately [33]. If EGFR mutation is identified in one synchronous lung primary tumour, targeted therapy should be applied according to the therapeutic guidelines [34].

When considering heterogeneity between the primary tumour and corresponding metastases, the percentage of discordant results of EGFR mutation status varied from $0 \%$ to $38.8 \%$ (table 3) [23, 32, 35-39]. The genetic profiles of metastatic tumours might evolve or be clonally selected when metastasis occurs, and the time interval between primary tumour and metastasis is sufficiently long for outgrowth of heterogeneous subpopulations. In addition, chemotherapy or TKI therapy may affect EGFR mutation status by changing the overall frequency of EGFR mutant clones after drug treatment [19, 29]. Therefore, in a small subset of patients, primary tumours may not be representative of the EGFR mutation status of the metastatic tumours. The CAP/IASLC/AMP guideline suggested that EGFR mutation testing with cytological or small biopsy samples from the primary tumour or its metastases might be equally suitable for tumour genotyping [33]. In fact, in a population-based EGFR testing programme, SHIAU et al. [40] reported that close to $80 \%$ of submitted archival samples are from the primary tumour. However, for other genomic profiling studies, no guideline has been established as to whether the primary tumour or metastasis might be appropriate for molecular analysis. The clinical significance of genetic heterogeneity remains to be fully evaluated in future studies.

Among multiple candidate lesions, the selection of the biopsy site for molecular tests is usually based on tumour size and accessibility [2, 41]. Imaging may be used to guide biopsy and avoid necrotic areas. Bony metastases that require a decalcification process are not ideal for molecular analysis.

For a better understanding of the genetic mechanisms of response and resistance to targeted therapies, and for procurement of biological specimens for further research, sequential tumour biopsies at different timepoints during the course of disease or treatment are encouraged [2]. If additional samples need to be obtained, several clinical factors such as the patient's overall clinical condition, accessibility of lesions, radiographic features, responsiveness to previous therapies and the most proper time-point should be considered $[2,33]$.

\section{The type of sample for molecular testing}

Pathological diagnosis and classification can be accurately made in most small biopsy and cytology specimens with few tumour cells, as they depend mainly on recognising the morphological (qualitative) features of the tumour cells. By contrast, molecular tests tend to require more tissue as assay sensitivity may require minimum amount of material (e.g. DNA, RNA or tumour cells). More tumour tissue also provides greater areas to enrich for the tumour cell contents by macro- or microdissection [33]. 


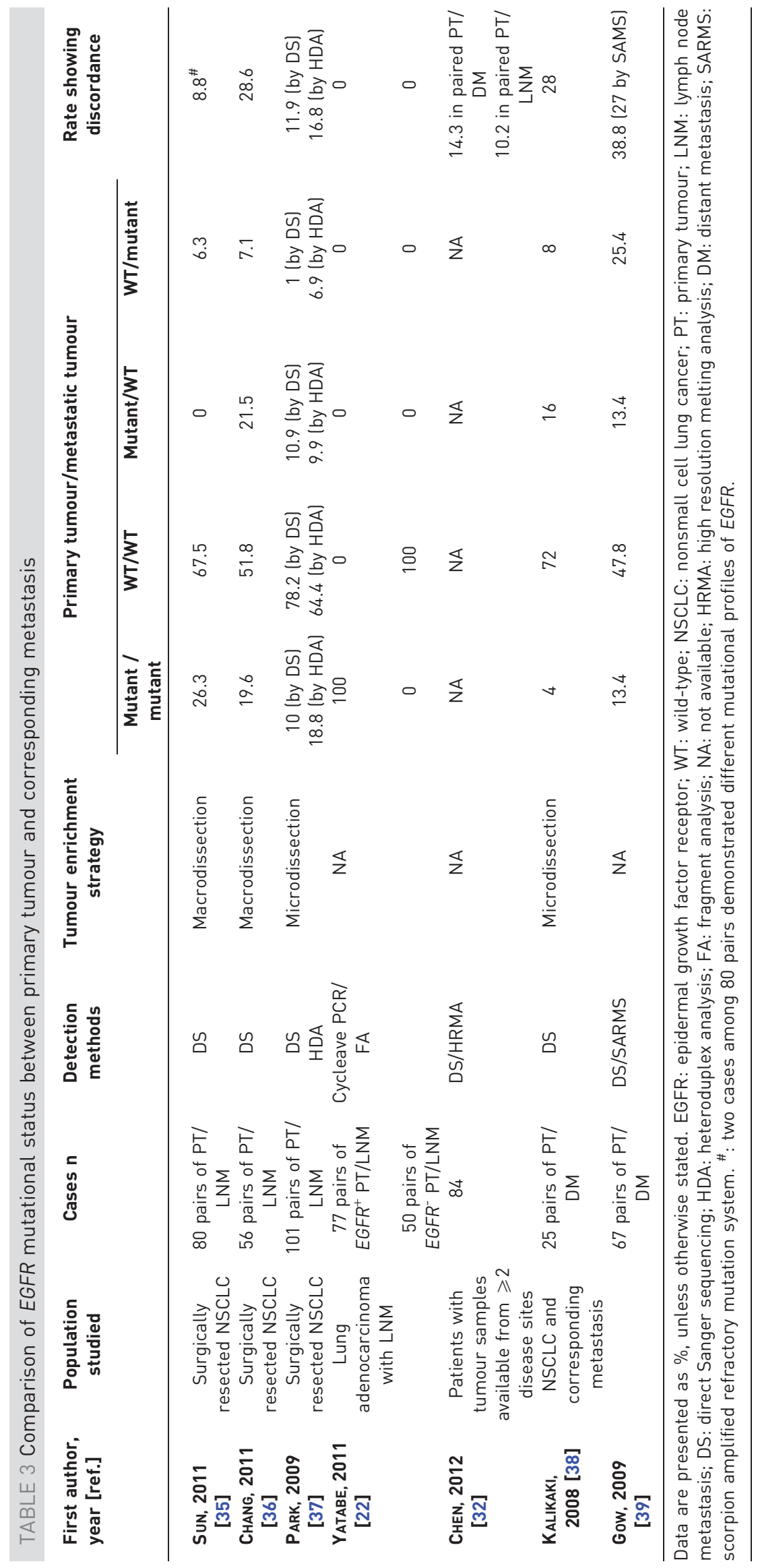


Less than $30 \%$ of NSCLCs are resectable at the time of presentation [1]. Therefore, most clinical samples from patients with advanced-stage lung cancer available for molecular testing are small, formalin-fixed and paraffin-embedded (FFPE) biopsies or cytological specimens. Paradoxically, while the number of biomarkers for testing per specimen has been increasing, tumour sampling has moved towards favouring less invasive procedures, which usually yield a smaller amount of sample. Small specimens may contain limited amounts of tumour cells and a variable proportion of non-neoplastic cells, which can affect the accuracy of the results (fig. 1). Therefore, limiting the use of ancillary diagnostic immunohistochemistry markers and clinical prioritisation of molecular testing is important [42]. The requirement for larger and multiple biopsy samples needs to be balanced by the risk of procedural morbidity, such as pneumothorax or haemoptysis [43]. The data on the number of biopsies or cores that can be obtained from one lesion are limited [43-45], despite guidelines emphasising the benefits of obtaining as much tumour tissue as possible [41].

Although using tissue specimens is the gold standard for molecular testing, a considerable fraction of advanced stage NSCLC patients are diagnosed by cytology only [46]. Previous studies have demonstrated that, if FFPE samples are not available, a cytology sample can be appropriate for accurate diagnosis as well as for molecular testing $[46,47]$. The detection rates of EGFR mutation with cytology specimens seem to be as high as those with tissue samples [40, 47]. However, more sensitive mutation testing methods should be applied when cytology samples have low tumour cell content [28]. Diagnostic fine needle aspiration (FNA) specimens often have an inherently high proportion of tumour cells [48], as tumour cells are less cohesive and, thus, are more easily aspirated out. FNA samples archived for a long time have been shown to yield abundant genomic DNA suitable for molecular profiling [49]. A recent study demonstrated that the tumour cells selectively scraped from smeared slides yielded high quality nucleic acid for molecular analysis [49], and showed significantly higher overall tumour cell numbers and tumour cellularity than cell block specimens [50]. However, cell block specimens are generally preferred over smear slides because tumour cellularity in cell block sections can be easily assessed, the original diagnostic slides can be archived and additional ancillary tests are possible when necessary [51].

In cases when biopsy or cytology samples cannot be obtained, the patient's plasma might become an option. Plasma samples may contain circulating free DNA released from the tumour cells or circulating tumour cells. The concordance rates of the mutation status between plasma and tumour samples are variable from $33 \%$ to $87 \%$ according to the study design, the detection methods and the eligible patient groups [52-54]. Although technological advances have led to more accurate detection of cancer-associated alleles in the blood, many hurdles still need to be overcome before routine clinical application [52]. Nevertheless, plasma may provide information on the genetic landscape of tumours overcoming genetic heterogeneity and offering the opportunity to assess tumour dynamics, such as detection of minimal residual disease, early detection of recurrence and prediction of response to treatment in the advanced stage of lung cancer [12]. It shows promise in providing the least invasive and most convenient and cost-effective way of obtaining samples for molecular testing in the future.

\section{The amount of tumour cells for molecular testing}

In general, the amount of cells and the concentration of the extracted DNA is less of an issue in most mutational analysis using frozen samples [55]. The cytology specimen, as well as small biopsy samples that yield a very low amount of DNA, can detect mutations when using more sensitive detection methods
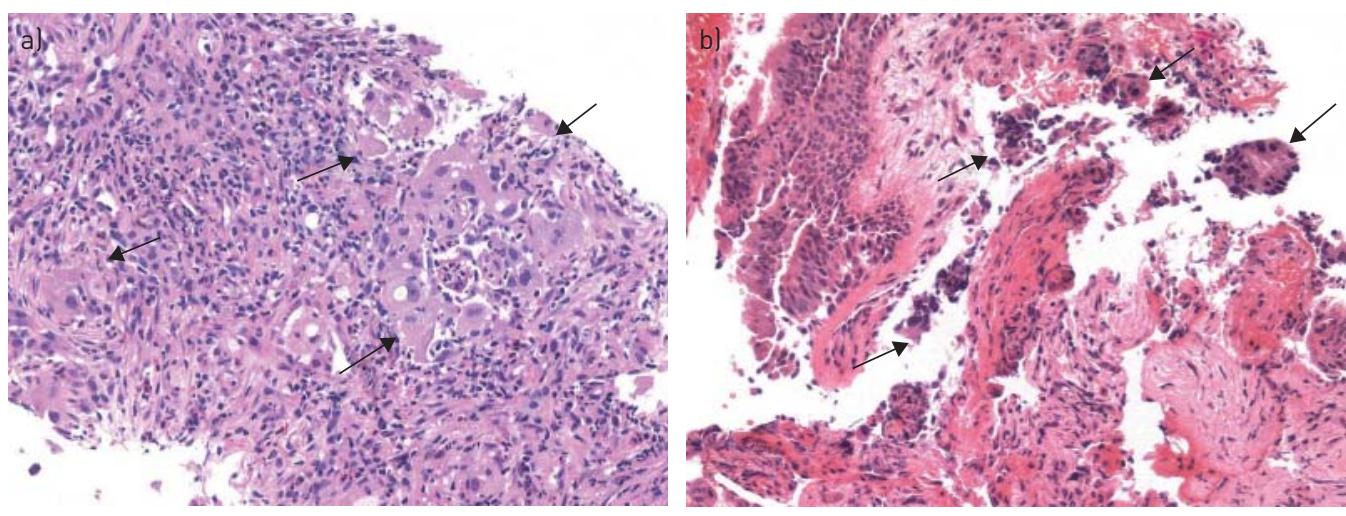

FIGURE 1 The histological features of a) needle core and b) bronchoscopic biopsy samples. Some biopsy tissues contain only small amounts of tumour cells (arrows) mixed with an overwhelming number of non-neoplastic cells including bronchial epithelial cells, inflammatory cells and fibroblasts (haematoxylin and eosin stain; $100 \times$ original magnification). 
[40, 42, 56-58]. However, with $<300$ cells, the risk of an insufficient result increases due to a higher chance of artifactual mutations in formalin fixed specimens [55]. The number of cells required for a successful mutation test has not been well defined, but a range of 100-400 tumour cells in the specimen has been suggested [41, 45, 59]. Another study reported that cytological specimens satisfying any of the following three criteria: DNA concentration $>25 \mathrm{ng} \cdot \mu \mathrm{L}^{-1},>30$ tumour cells or $>30 \%$ tumour cellularity; demonstrated $100 \%$ concordance with the corresponding tissue samples when using a pyrosequencing method [50]. In population-based EGFR mutation testing of 2293 cases, SHIAU et al. [40] reported that among surgical biopsy specimens tested, core biopsy of the primary lung lesions had the highest test-failure rate $(\sim 10 \%)$. The highest test success-rate was associated with $\geqslant 30 \%$ tumour cellularity within the macrodissection area, and $\mathrm{a} \geqslant 2 \mathrm{~mm}$ tumour area marked for macrodissection. For cytology samples, only overall cell content of the cell block, but not tumour cellularity, was correlated with test-success rates, with minimal cell content cases reporting significantly lower test-success rates than cases with small clusters of abundant cell content.

\section{Specimen quality: tumour cellularity and tumour cell enrichment}

Preservation and quality of the amplifiable DNA seemed to be more important than its quantity in the samples $[41,60]$. If multiple specimens are available for molecular testing, the choice of which sample is the best for molecular assays should be based on the quality of the specimen, percentage tumour cellularity and the validated specimen type in each laboratory [34]. False-negative results may be problematic when only small samples are available for molecular testing, as the detection sensitivity may be further diminished by the pre-analytical histological or cytological factors.

The relative proportion of tumour cells versus non-neoplastic cells is one of the important parameters that determine the sensitivity of molecular testing $[42,60]$. Yet, there is no definite consensus on optimal tumour cellularity or how to assess it. Some groups have set thresholds for $>60 \%$ tumour cellularity and $<20 \%$ necrosis for comprehensive genomic analysis [61-63]. For Sanger sequencing, if heterozygosity and disomic tumour cells are considered, the suggested threshold for reliable results is $40-50 \%$ when tumour cellularity is estimated and $30 \%$ when more accurate counting is performed $[41,56]$. However, mutations may also be detected in samples with $<40 \%$ tumour cellularity. The correlation between mutated allele frequency and tumour cellularity is highly influenced by gene copy number changes, as EGFR-mutated alleles are preferentially amplified [64-66].

As considerable variation in the tumour cellularity between samples may exist, a histological evaluation of each sample to confirm the diagnosis and assess the tumour cellularity is critical [2]. However, estimation of tumour cellularity can vary significantly among pathologists [56, 67-69], and visual assessment with estimation of tumour cellularity may have a tendency to overestimate tumour cellularity when compared with cell number counting $[56,68]$. The training of pathologists with gold standard calibration specimens might be helpful for more consistent estimations of tumour cellularity [33, 67]. The development of computational image analysis systems for accurate counting of the cellular content may be an alternate unbiased option for estimating tumour cellularity [70].

An ideal specimen for molecular testing would have a high proportion of tumour cells and a minimal amount of mucin or necrotic cells. To obtain the best quality of specimens, techniques to enrich for tumour cells can be applied. Pathologists can designate the tumour cell rich areas on the slides during the histological review of the case and scrape off these areas from an unstained section, or alternatively core out the marked area from the paraffin block. Flow cytometric sorting or laser-captured microdissection techniques can be also used, but they are not practical or suitable in clinical practice.

With the rapid advance in detection methods with increasing sensitivity the analytical limitation of tumour cellularity lessens, and samples with lower tumour cellularity can be molecularly profiled. The CAP/IASLC/AMP guidelines recommended that, for EGFR-targeted therapy, sensitive molecular methods that can detect mutations in specimens with as little as $10 \%$ tumour cells should be available [33]. Each laboratory should also validate its sensitivity threshold for each assay and for each specimen type. However, the results of ultrasensitive molecular assays with a sensitivity of below $1 \%$ should be carefully interpreted due to an increased chance of artifactual mutations. The tumour cellularity of the samples and the detection limit of the molecular assay should always be considered together $[28,69]$. In addition, the significance of very low frequency EGFR mutations detected with ultrasensitive methods should also be validated.

\section{Pre-analytical processing of the specimens}

The quality of a specimen is primarily influenced by pre-fixation time, the type of fixative and fixation time. Significant biochemical alterations start to occur in tissues within $10 \mathrm{~min}$ after sampling or resection. The pre-fixation time should be minimised to reduce the degradation of RNA and protein. The gross 
examination of the resected specimen and sectioning into thin slices should be performed as soon as possible to facilitate the penetration of the fixatives [71].

Fresh, frozen, formalin-fixed or alcohol-fixed specimens can be used for molecular analysis. Fixation with $10 \%$ neutral-buffered formalin is routinely used to preserve clinical tissue specimens. However, formalin fixation is not optimal for molecular analyses as it causes chemical cross-linking of proteins, and fragmentation and chemical modification of nucleic acids [72, 73]. Random base alterations that generate artefactual mutations can occur, typically in FFPE samples with low DNA concentration [55, 74]. Nevertheless, formalin fixation preserves morphological details and allows long-term storage of samples at very low cost. Furthermore, most ancillary tests, including immunohistochemistry and molecular assays, have now been optimised and validated for use on FFPE samples, and many high-throughput techniques are being optimised for application to these samples [75, 76]. Clinical testing of EGFR mutations and ALK gene rearrangement can be reliably performed using FFPE samples.

Frozen specimen provides a high quality of nucleic acids and proteins, and has been considered the most optimal sample for most molecular analysis. However, freezing does not preserve the morphological details of tissues well and the handling and storing of frozen samples requires highly controlled conditions and costly infrastructure. Alcohol fixation generates a superior yield of nucleic acid compared with formalin, as it does not cause the chemical changes found in formalin-fixed specimens [71, 77]. As most fixatives for cytology preparation are alcohol bases, cytology specimens are appropriate for DNA-based molecular assays [42]. However, they may alter the morphological details of the nucleus, and are not recommended for tests that still depend on morphological evaluation, including fluorescent in situ hybridisation (FISH) [78]. Heavy metal fixatives are not suitable for most molecular analyses because they cause DNA fragmentation, and the metals in the fixative compete with magnesium and interact with other enzymes that are critical in molecular assays [79-81]. Bone is a common site for metastatic spread of lung cancer. Decalcification of the specimens obtained from bony metastases should be avoided and tissues treated with decalcifying solutions should not be used for molecular testing, as decalcifying solutions extensively degrade DNA [34]. This can be overcome by using non-acid EDTA-containing decalcification solutions.

Optimal fixation time for molecular analysis is $6-12 \mathrm{~h}$ for small biopsy samples and $8-19 \mathrm{~h}$ for larger surgical specimens [41]. The recent guidelines suggest that fixation times of 6-48 h are acceptable for clinical molecular tests $[33,82]$. A fixation time $<6 \mathrm{~h}$ is not recommended, since haematoxylin and eosin staining, immunohistochemistry and FISH analysis are adversely affected. If the fixation time exceeds $48 \mathrm{~h}$, the quality of DNA deteriorates [72], and signals in FISH analysis become weaker [78].

TABLE 4 Recommendations for pre-analytical preparation for molecular analysis in advanced lung cancer patients

Selection of biopsy site

Primary tumour versus metastasis: equally suitable

Necrotic mass or bone metastasis: not suitable Multiple synchronous primary tumours: each may be tested

Multiple-site biopsy in one tumour: not necessary

Sampling

Sequential biopsies at different time point: optional

Biopsy is preferred over cytology

Obtain as much tumour tissue as clinically feasible

If only cytology is available, cell block is preferred

Plasma: needs further evaluation

Fixation

Pre-fixation time should be minimised

Formalin fixation is recommended for biopsy specimen

Heavy metal fixatives or non-EDTA decalcifying solution should be avoided

Fixation time: ideally $\geqslant 6 \mathrm{~h}$, but $<48 \mathrm{~h}$

Pathologic diagnosis

Limit the amount of immunohistochemistry for histological subtyping

Preserve maximum amount of specimen for molecular testing

ADC/NSCLC with ADC component and nonsmokers or light smokers: submit specimen for EGFR and ALK testing

Tumour cell content

$\geqslant 40 \%$ for Sanger sequencing

Lower tumour cell content acceptable with higher (1-10\%) sensitivity techniques

Tumour cell enrichment with macro- or microdissection: recommended

ADC: adenocarcinoma; NSCLC: nonsmall cell carcinoma; EGFR: epidermal growth factor receptor; ALK: anaplastic lymphoma kinase. 


\section{The role of the pathologists}

In the era of personalised therapy, pathologists play an important role as a bridge between molecular testing and the clinical oncologists. Communication between the pathologist and the clinician is very important in determining the priority of the tests for individual patients. When the specimens are obtained, the clinical data such as tumour stage and treatment plan are often not readily available. Therefore, it is judicious to handle small diagnostic samples carefully, keeping in mind that they might be the only sample available for molecular testing. The pathologists should be involved in all steps from sampling of the specimen to ensure an adequate amount of specimen is obtained and to keep the specimens in good condition for molecular analysis (table 4).

After the diagnosis of malignancy is established, further histological subtyping of lung cancer is relevant for determining molecular testing strategies. Most tumours harbouring EGFR mutations as well as ALK gene rearrangement are adenocarcinomas or nonsmall cell lung carcinomas with an adenocarcinoma component [33]. A small biopsy or cytology sample showing histological subtypes other than adenocarcinoma does not exclude the presence of an adenocarcinoma component in the non-biopsied lesion. Additionally, the discrimination between adenocarcinoma and squamous cell carcinoma can be challenging in small biopsy samples. Therefore, the guideline suggested that if the histological subtype is uncertain or when squamous or small cell carcinoma patients have clinical features favouring EGFR mutation-positive subsets (e.g. nonsmokers), it is best to send the sample for molecular testing [33].

Because EGFR and ALK testing are the most important steps for therapeutic decision making after a diagnosis of adenocarcinoma is established, the CAP/IASLC/AMP guideline recommends preservation of a maximum amount of specimen for potential molecular testing and limitation on the amount of immunohistochemistry staining for histological subtyping [33]. For tumours with equivocal morphological features, e.g. NSCLC with not otherwise specified feature, it has been recommended that only one or two ancillary stains for each subtype be applied: thyroid transcription factor-1/napsin-A/mucin for adenocarcinoma and $\mathrm{p} 63 / \mathrm{p} 40$ or cytokeratin $5 / 6$ for squamous differentiation [83, 84]. If the immunohistochemistry study fails to result in a more specific diagnosis, the remaining tissue should be submitted for molecular testing, rather than further exhaustion of specimen for subtyping [34]. All specimens available from a patient including cytology samples should be considered for testing, and the choice of which specimen would be the most adequate for testing should be determined by a pathologist based on the specimen quality [33, 46, 47].

Reflex molecular testing ordered by the pathologist at the time of initial diagnosis would provide a more readily available molecular profile when the oncologist sees the patient, but the pathologist should communicate closely with institutional clinicians on which tests should be prioritised according to the individual patient's need. Reflex preparation of the block, which involves cutting multiple additional unstained sections when the sample is processed initially in expectation of additional immunohistochemistry or molecular testing, may prevent waste of tissue by avoiding the re-cutting of blocks [34]. The essential information should be shared among clinical oncologists, pathologists and molecular pathologists. This can improve diagnosis accuracy and avoid waste of material that is intended for use in molecular analyses.

\section{Conclusions}

For the genomic profiling of lung cancer patients who will benefit from targeted therapy, sampling of tumour tissue that can be taken as representative of the malignancy, and that is adequate in quantity and quality is critical. Tumour specimens should be obtained as far as possible at the time of biopsy. A system of rapid on-site evaluation by a pathologist or well-trained technician to assure adequacy of the sample is desirable in cytological aspiration biopsies. Specimen quality such as tumour cellularity as well as preservation and fixation status is crucial for optimal molecular analysis. The significance of genetic heterogeneity of the tumour requires further investigation, and the significance and clinical application of multiplex mutational analysis or next-generation sequencing is currently being evaluated in many centres. The close communication between clinical oncologists, pathologists and molecular pathologists is critical to ensure the most optimal way of obtaining adequate tumour tissues for accurate histopathological diagnosis and molecular testing, and the proper guidance of treatment strategy for personalised cancer therapy.

\section{References}

1 Molina JR, Yang P, Cassivi SD, et al. Non-small cell lung cancer: epidemiology, risk factors, treatment, and survivorship. Mayo Clin Proc 2008; 83: 584-594.

2 Basik M, Aguilar-Mahecha A, Rousseau C, et al. Biopsies: next-generation biospecimens for tailoring therapy. Nat Rev Clin Oncol 2013; 10: 437-450.

3 Paez JG, Jänne PA, Lee JC, et al. EGFR mutations in lung cancer: correlation with clinical response to gefitinib therapy. Science 2004; 304: 1497-1500. 
Lynch TJ, Bell DW, Sordella R, et al. Activating mutations in the epidermal growth factor receptor underlying responsiveness of non-small-cell lung cancer to gefitinib. N Engl J Med 2004; 350: 2129-2139.

$5 \quad$ Kwak EL, Bang YJ, Camidge DR, et al. Anaplastic lymphoma kinase inhibition in non-small-cell lung cancer. $N$ Engl J Med 2010; 363: 1693-703.

6 Mok TS, Wu YL, Thongprasert S, et al. Gefitinib or carboplatin-paclitaxel in pulmonary adenocarcinoma. $N$ Engl J Med 2009; 361: 947-957.

7 Mitsudomi T, Morita S, Yatabe Y, et al. Gefitinib versus cisplatin plus docetaxel in patients with non-small-cell lung cancer harbouring mutations of the epidermal growth factor receptor (WJTOG3405): an open label, randomised phase 3 trial. Lancet Oncol 2010; 11: 121-128.

8 Zhou C, Wu YL, Chen G, et al. Erlotinib versus chemotherapy as first-line treatment for patients with advanced EGFR mutation-positive non-small-cell lung cancer (OPTIMAL, CTONG-0802): a multicentre, open-label, randomised, phase 3 study. Lancet Oncol 2011; 12: 735-742.

9 Rosell R, Carcereny E, Gervais R, et al. Erlotinib versus standard chemotherapy as first-line treatment for European patients with advanced EGFR mutation-positive non-small-cell lung cancer (EURTAC): a multicentre, open-label, randomised phase 3 trial. Lancet Oncol 2012; 13: 239-246.

10 Shaw AT, Kim DW, Nakagawa K, et al. Crizotinib versus chemotherapy in advanced ALK-positive lung cancer. $N$ Engl J Med 2013; 368: 2385-2394.

11 Beau-Faller M, Degeorges A, Rolland E, et al. Cross-validation study for epidermal growth factor receptor and KRAS mutation detection in 74 blinded non-small cell lung carcinoma samples: a total of 5550 exons sequenced by 15 molecular French laboratories (evaluation of the EGFR mutation status for the administration of EGFR-TKIs in non-small cell lung carcinoma [ERMETIC] project-part 1). J Thorac Oncol 2011; 6: 1006-1015.

12 Crowley E, Di Nicolantonio F, Loupakis F, et al. Liquid biopsy: monitoring cancer-genetics in the blood. Nat Rev Clin Oncol 2013; 10: 472-484.

13 Gerlinger M, Rowan AJ, Horswell S, et al. Intratumor heterogeneity and branched evolution revealed by multiregion sequencing. N Engl J Med 2012; 366: 883-892.

14 Vignot S, Frampton GM, Soria JC, et al. Next-generation sequencing reveals high concordance of recurrent somatic alterations between primary tumor and metastases from patients with non-small-cell lung cancer. J Clin Oncol 2013; 31: 2167-2172.

15 Ding L, Ellis MJ, Li S, et al. Genome remodelling in a basal-like breast cancer metastasis and xenograft. Nature 2010; 464: 999-1005.

16 Jakobsen JN, Sørensen JB. Intratumor heterogeneity and chemotherapy-induced changes in EGFR status in nonsmall cell lung cancer. Cancer Chemother Pharmacol 2012; 69: 289-299.

17 Jiang SX, Yamashita K, Yamamoto M, et al. EGFR genetic heterogeneity of nonsmall cell lung cancers contributing to acquired gefitinib resistance. Int J Cancer 2008; 123: 2480-2486.

18 Taniguchi K, Okami J, Kodama K, et al. Intratumor heterogeneity of epidermal growth factor receptor mutations in lung cancer and its correlation to the response to gefitinib. Cancer Sci 2008; 99: 929-935.

19 Bai H, Wang Z, Chen K, et al. Influence of chemotherapy on EGFR mutation status among patients with nonsmall-cell lung cancer. J Clin Oncol 2012; 30: 3077-3083.

20 Bai H, Wang Z, Wang Y, et al. Detection and clinical significance of intratumoral EGFR mutational heterogeneity in Chinese patients with advanced non-small cell lung cancer. PLoS One 2013; 8: e54170.

21 Tomonaga N, Nakamura Y, Yamaguchi H, et al. Analysis of intratumor heterogeneity of EGFR mutations in mixed type lung adenocarcinoma. Clin Lung Cancer 2013; 14: 521-526.

22 Yatabe Y, Matsuo K, Mitsudomi T. Heterogeneous distribution of EGFR mutations is extremely rare in lung adenocarcinoma. J Clin Oncol 2011; 29: 2972-2977.

23 Sun PL, Seol H, Lee HJ, et al. High incidence of EGFR mutations in Korean men smokers with no intratumoral heterogeneity of lung adenocarcinomas: correlation with histologic subtypes, EGFR/TTF-1 expressions, and clinical features. J Thorac Oncol 2012; 7: 323-330.

24 Mattsson JS, Imgenberg-Kreuz J, Edlund K, et al. Consistent mutation status within histologically heterogeneous lung cancer lesions. Histopathology 2012; 61: 744-748.

25 Marchetti A, Del Grammastro M, Filice G, et al. Complex mutations and subpopulations of deletions at exon 19 of EGFR in NSCLC revealed by next generation sequencing: potential clinical implications. PLoS One 2012; 7: e42164.

26 Solomon SB, Zakowski MF, Pao W, et al. Core needle lung biopsy specimens: adequacy for EGFR and KRAS mutational analysis. AJR Am J Roentgenol 2010; 194: 266-269.

27 Masago K, Fujita S, Mio T, et al. Accuracy of epidermal growth factor receptor gene mutation analysis by direct sequencing method based on small biopsy specimens from patients with non-small cell lung cancer: analysis of results in 19 patients. Int J Clin Oncol 2008; 13: 442-446.

28 Han HS, Lim SN, An JY, et al. Detection of EGFR mutation status in lung adenocarcinoma specimens with different proportions of tumor cells using two methods of differential sensitivity. J Thorac Oncol 2012; 7: 355-364.

29 Honda Y, Takigawa N, Fushimi S, et al. Disappearance of an activated EGFR mutation after treatment with EGFR tyrosine kinase inhibitors. Lung Cancer 2012; 78: 121-124.

30 Sakurada A, Lara-Guerra H, Liu N, et al. Tissue heterogeneity of EGFR mutation in lung adenocarcinoma. $J$ Thorac Oncol 2008; 3: 527-529.

31 Querings S, Altmüller J, Ansén S, et al. Benchmarking of mutation diagnostics in clinical lung cancer specimens. PLoS One 2011; 6: e19601.

32 Chen ZY, Zhong WZ, Zhang XC, et al. EGFR mutation heterogeneity and the mixed response to EGFR tyrosine kinase inhibitors of lung adenocarcinomas. Oncologist 2012; 17: 978-985.

33 Lindeman NI, Cagle PT, Beasley MB, et al. Molecular testing guideline for selection of lung cancer patients for EGFR and ALK tyrosine kinase inhibitors: guideline from the College of American Pathologists, International Association for the Study of Lung Cancer, and Association for Molecular Pathology. J Thorac Oncol 2013; 8: 823-859.

34 Aisner DL, Marshall CB. Molecular pathology of non-small cell lung cancer: a practical guide. Am J Clin Pathol 2012; 138: 332-346.

35 Sun L, Zhang Q, Luan H, et al. Comparison of KRAS and EGFR gene status between primary non-small cell lung cancer and local lymph node metastases: implications for clinical practice. J Exp Clin Cancer Res 2011; 30: 30. 
36 Chang YL, Wu CT, Shih JY, et al. Comparison of p53 and epidermal growth factor receptor gene status between primary tumors and lymph node metastases in non-small cell lung cancers. Ann Surg Oncol 2011; 18: 543-550.

37 Park S, Holmes-Tisch AJ, Cho EY, et al. Discordance of molecular biomarkers associated with epidermal growth factor receptor pathway between primary tumors and lymph node metastasis in non-small cell lung cancer. J Thorac Oncol 2009; 4: 809-815.

38 Kalikaki A, Koutsopoulos A, Trypaki M, et al. Comparison of EGFR and K-RAS gene status between primary tumours and corresponding metastases in NSCLC. Br J Cancer 2008; 99: 923-929.

39 Gow CH, Chang YL, Hsu YC, et al. Comparison of epidermal growth factor receptor mutations between primary and corresponding metastatic tumors in tyrosine kinase inhibitor-naive non-small-cell lung cancer. Ann Oncol 2009; 20: 696-702.

40 Shiau CJ, Babwah JP, da Cunha Santos G, et al. Sample features associated with success rates in population-based EGFR mutation testing. J Thorac Oncol 2014; 9: 947-956.

41 Pirker R, Herth FJ, Kerr KM, et al. Consensus for EGFR mutation testing in non-small cell lung cancer: results from a European workshop. J Thorac Oncol 2010; 5: 1706-1713.

42 Aisner DL, Deshpande C, Baloch Z, et al. Evaluation of EGFR mutation status in cytology specimens: an institutional experience. Diagn Cytopathol 2013; 41: 316-323.

43 Gellert AR, Rudd RM, Sinha G, et al. Fibreoptic bronchoscopy: effect of multiple bronchial biopsies on diagnostic yield in bronchial carcinoma. Thorax 1982; 37: 684-687.

44 Lee HS, Lee GK, Lee HS, et al. Real-time endobronchial ultrasound-guided transbronchial needle aspiration in mediastinal staging of non-small cell lung cancer: how many aspirations per target lymph node station? Chest 2008; 134: $368-374$.

45 Tam AL, Kim ES, Lee JJ, et al. Feasibility of image-guided transthoracic core-needle biopsy in the BATTLE lung trial. J Thorac Oncol 2013; 8: 436-442.

46 Malapelle U, Bellevicine C, Zeppa P, et al. Cytology-based gene mutation tests to predict response to anti-epidermal growth factor receptor therapy: a review. Diagn Cytopathol 2011; 39: 703-710.

47 Rekhtman N, Brandt SM, Sigel CS, et al. Suitability of thoracic cytology for new therapeutic paradigms in nonsmall cell lung carcinoma: high accuracy of tumor subtyping and feasibility of EGFR and KRAS molecular testing. J Thorac Oncol 2011; 6: 451-458.

48 Ellison G, Zhu G, Moulis A, et al. EGFR mutation testing in lung cancer: a review of available methods and their use for analysis of tumour tissue and cytology samples. J Clin Pathol 2013; 66: 79-89.

49 Killian JK, Walker RL, Suuriniemi M, et al. Archival fine-needle aspiration cytopathology (FNAC) samples: untapped resource for clinical molecular profiling. J Mol Diagn 2010; 12: 739-745.

50 Sun PL, Jin Y, Kim H, et al. High concordance of EGFR mutation status between histologic and corresponding cytologic specimens of lung adenocarcinomas. Cancer Cytopathol 2013; 121: 311-319.

51 da Cunha Santos G, Saieg MA, Geddie W, et al. EGFR gene status in cytological samples of nonsmall cell lung carcinoma: controversies and opportunities. Cancer Cytopathol 2011; 119: 80-91.

52 Brevet M, Johnson ML, Azzoli CG, et al. Detection of EGFR mutations in plasma DNA from lung cancer patients by mass spectrometry genotyping is predictive of tumor EGFR status and response to EGFR inhibitors. Lung Cancer 2011; 73: 96-102.

53 Nakamura T, Sueoka-Aragane N, Iwanaga K, et al. Application of a highly sensitive detection system for epidermal growth factor receptor mutations in plasma DNA. J Thorac Oncol 2012; 7: 1369-1381.

54 Bai H, Mao L, Wang HS, et al. Epidermal growth factor receptor mutations in plasma DNA samples predict tumor response in Chinese patients with stages IIIB to IV non-small-cell lung cancer. J Clin Oncol 2009; 27: 2653-2659.

55 Williams C, Pontén F, Moberg C, et al. A high frequency of sequence alterations is due to formalin fixation of archival specimens. Am J Pathol 1999; 155: 1467-1471.

56 Warth A, Penzel R, Brandt R, et al. Optimized algorithm for Sanger sequencing-based EGFR mutation analyses in NSCLC biopsies. Virchows Arch 2012; 460: 407-414.

57 Smith GD, Chadwick BE, Willmore-Payne C, et al. Detection of epidermal growth factor receptor gene mutations in cytology specimens from patients with non-small cell lung cancer utilising high-resolution melting amplicon analysis. J Clin Pathol 2008; 61: 487-493.

58 Molina-Vila MA, Bertran-Alamillo J, Reguart N, et al. A sensitive method for detecting EGFR mutations in nonsmall cell lung cancer samples with few tumor cells. J Thorac Oncol 2008; 3: 1224-1235.

59 Savic S, Tapia C, Grilli B, et al. Comprehensive epidermal growth factor receptor gene analysis from cytological specimens of non-small-cell lung cancers. Br J Cancer 2008; 98: 154-160.

60 Thunnissen E, Kerr KM, Herth FJ, et al. The challenge of NSCLC diagnosis and predictive analysis on small samples. Practical approach of a working group. Lung Cancer 2012; 76: 1-18.

61 Cancer Genome Atlas Research Network. Integrated genomic analyses of ovarian carcinoma. Nature 2011; 474: 609-615.

62 Cancer Genome Atlas Network. Comprehensive molecular characterization of human colon and rectal cancer. Nature 2012; 487: 330-337.

63 Cancer Genome Atlas Research Network. Comprehensive genomic characterization of squamous cell lung cancers. Nature 2012; 489: 519-525.

64 Soh J, Okumura N, Lockwood WW, et al. Oncogene mutations, copy number gains and mutant allele specific imbalance (MASI) frequently occur together in tumor cells. PLoS One 2009; 4: e7464.

65 Zhu CQ, da Cunha Santos G, Ding K, et al. Role of KRAS and EGFR as biomarkers of response to erlotinib in National Cancer Institute of Canada Clinical Trials Group Study BR.21. J Clin Oncol 2008; 26: 4268-4275.

66 Fukuoka M, Wu YL, Thongprasert S, et al. Biomarker analyses and final overall survival results from a phase III, randomized, open-label, first-line study of gefitinib versus carboplatin/paclitaxel in clinically selected patients with advanced non-small-cell lung cancer in Asia (IPASS). J Clin Oncol 2011; 29: 2866-2874.

67 Smits AJ, Kummer JA, de Bruin PC, et al. The estimation of tumor cell percentage for molecular testing by pathologists is not accurate. Mod Pathol 2014; 27: 168-174.

68 Viray H, Li K, Long TA, et al. A prospective, multi-institutional diagnostic trial to determine pathologist accuracy in estimation of percentage of malignant cells. Arch Pathol Lab Med 2013; 137: 1545-1549. 
Deans ZC, Bilbe N, O'Sullivan B, et al. Improvement in the quality of molecular analysis of EGFR in non-small-cell lung cancer detected by three rounds of external quality assessment. J Clin Pathol 2013; 66: 319-325.

70 Yuan Y, Failmezger H, Rueda OM, et al. Quantitative image analysis of cellular heterogeneity in breast tumors complements genomic profiling. Sci Transl Med 2012; 4: 157ra43.

71 Srinivasan M, Sedmak D, Jewell S. Effect of fixatives and tissue processing on the content and integrity of nucleic acids. Am J Pathol 2002; 161: 1961-1971.

72 Foss RD, Guha-Thakurta N, Conran RM, et al. Effects of fixative and fixation time on the extraction and polymerase chain reaction amplification of RNA from paraffin-embedded tissue. Comparison of two housekeeping gene mRNA controls. Diagn Mol Pathol 1994; 3: 148-155.

73 Chalkley R, Hunter C. Histone-histone propinquity by aldehyde fixation of chromatin. Proc Natl Acad Sci USA 1975; 72: 1304-1308.

74 Wong C, DiCioccio RA, Allen HJ, et al. Mutations in BRCA1 from fixed, paraffin-embedded tissue can be artifacts of preservation. Cancer Genet Cytogenet 1998; 107: 21-27.

75 Holley T, Lenkiewicz E, Evers L, et al. Deep clonal profiling of formalin fixed paraffin embedded clinical samples. PLoS One 2012; 7: e50586.

76 Tuononen K, Mäki-Nevala S, Sarhadi VK, et al. Comparison of targeted next-generation sequencing (NGS) and real-time PCR in the detection of EGFR, KRAS, and BRAF mutations on formalin-fixed, paraffin-embedded tumor material of non-small cell lung carcinoma-superiority of NGS. Genes Chromosomes Cancer 2013; 52: 503-511.

77 Gillespie JW, Best CJ, Bichsel VE, et al. Evaluation of non-formalin tissue fixation for molecular profiling studies. Am J Pathol 2002; 160: 449-457.

78 Babic A, Loftin IR, Stanislaw S, et al. The impact of pre-analytical processing on staining quality for H\&E, dual hapten, dual color in situ hybridization and fluorescent in situ hybridization assays. Methods 2010; 52: 287-300.

79 Tbakhi A, Totos G, Pettay JD, et al. The effect of fixation on detection of B-cell clonality by polymerase chain reaction. Mod Pathol 1999; 12: 272-278.

80 Baloglu G, Haholu A, Kucukodaci Z, et al. The effects of tissue fixation alternatives on DNA content: a study on normal colon tissue. Appl Immunohistochem Mol Morphol 2008; 16: 485-492.

81 Wilson IG. Inhibition and facilitation of nucleic acid amplification. Appl Environ Microbiol 1997; 63: 3741-3751.

82 Wolff AC, Hammond ME, Schwartz JN, et al. American Society of Clinical Oncology/College of American Pathologists guideline recommendations for human epidermal growth factor receptor 2 testing in breast cancer. J Clin Oncol 2007; 25: 118-145.

83 Terry J, Leung S, Laskin J, et al. Optimal immunohistochemical markers for distinguishing lung adenocarcinomas from squamous cell carcinomas in small tumor samples. Am J Surg Pathol 2010; 34: 1805-1811.

84 Pelosi G, Fabbri A, Bianchi F, et al. $\Delta \mathrm{Np} 63$ (p40) and thyroid transcription factor-1 immunoreactivity on small biopsies or cellblocks for typing non-small cell lung cancer: a novel two-hit, sparing-material approach. $J$ Thorac Oncol 2012; 7: 281-290. 